\title{
Evaluation of the Maternal Health Indicators: An Ecological Study from 2000 to 2014
}

\section{Dandara Rayssa Silva de Souza, Héllyda de Souza Bezerra, Julliane Tamara Araújo de Melo, Thaiza Teixeira Xavier Nobre, Fábia Barbosa de Andrade}

The Faculty of Health Sciences of Trairi (FACISA), Federal University of Rio Grande do Norte (UFRN), Santa Cruz, Rio Grande do Norte, Brazil

Email: dandara_rayssa@hotmail.com, hellydasbezerra@hotmail.com, tamara_bio@yahoo.com.br, thaizax@hotmail.com, fabiabarbosabr@yahoo.com.br

How to cite this paper: Souza, D.R.S., Bezerra, H.S., Melo, J.T.A., Nobre, T.T.X. and Andrade, F.B. (2018) Evaluation of the Maternal Health Indicators: An Ecological Study from 2000 to 2014. Health, 10, 251-267.

https://doi.org/10.4236/health.2018.102020

Received: July 31, 2017

Accepted: February 25, 2018

Published: February 28, 2018

Copyright (c) 2018 by authors and Scientific Research Publishing Inc. This work is licensed under the Creative Commons Attribution International License (CC BY 4.0).

http://creativecommons.org/licenses/by/4.0/

\begin{abstract}
The aiming of this worksheet is to evaluate and to compare the quantity of prenatal appointment indicators; childbirth by kind of delivery; maternal mortality coefficient and maternal deaths number. It is about an ecological, descriptive and analytical study, made through the appreciation of secondary data related to the maternal mortality in Rio Grande do Norte, from 2000 to 2014. To that, it was used information from SISPACTO to compare real data to the estimated goals. The results show that there was an increase on the number of women who performed seven or more prenatal queries, in turn, there was an increase of alive newborns through cesarean, moreover, it is observed an oscillation on the maternal deaths number by residence during the studied period, achieving superior values to the agreed goals during the last two analyzed years. It is concluded that the maternal health, in Rio Grande do Norte, negative indicators are being presented concerning the maternal mortality, in spite of presenting an improvement on the prenatal access.
\end{abstract}

\section{Keywords}

Prenatal Care, Maternal Mortality, Health Basic Indicators, Maternal Health Services

\section{Introduction}

The maternal health is constituted as primordial sector on the health public ambit, bearing in mind the great necessity to provide quality assistance to the women during the pregnancy-childbirth cycle and avoid grievances and complications due to this period, in which the woman is more prone to develop deter- 
mined pathological conditions due to many physiological and psychological changes inherent to the maternity.

This abstract has been focus of attention since the beginning of the industrialization process, so that the social movements for maternal health resulted in many public policies. However, the maternal mortality rate is still high over the years, what demonstrates the necessity to revalue those policies and their implementation, aiming to expand improvements in this field [1].

Even, it is stated that the maternal mortality reduction is a world concerning, being configured as the fifth millennium goal of the United Nations (UN), which aimed to decline in three quarters the maternal death rate from 1990 to 2015 [2].

The maternal mortality impact monitoring may contribute to the improvement of agencies and institutions, at the time that allows the opportunities, difficulties and challenges [3]. Moreover, allows the elaboration of new strategies and the evaluation of those already used, providing the strengthening of the maternal health.

Nevertheless, some factors hamper the real monitoring of the level and the maternal mortality tendency, as the sub formation and the sub-registration, resulting of the incorrect filling of the death declarations, when it is hidden that the death was related to the pregnancy, to the childbirth or to the postpartum, or for the non-registration of the death on the notary office. This is because of the ignorance by the professionals and the general population about the importance of that information and the document as health data source [4] [5] [6].

According to the International Statistical Classification of Diseases and Related Health Problems (ISCDRP), $10^{\text {th }}$ review, maternal death is the death of a woman that occurred during the pregnancy or in a period of 42 days after the pregnancy end, independently of the duration or the pregnancy place, or for measures took in relation to it, however not due to accidental or incidental causes [7].

Estimates state that, in 1990, approximately 585.000 maternal deaths occurred in the world. From those, only 5\% were in developed countries. In South America, about 28 thousand women died per year due to the complications resulting from the pregnancy, the childbirth or the postpartum [8].

A study [9] conducted in 2001, estimated that 600.000 women died per year in all the world, from maternal causes, and the most of the South America, the maternal death is one of the 10 main death causes of fertile age women, constituting one of the most relevant indicators evaluating the quality of the women health care services.

A study conducted in the Brazilian Northeast showed that half of the maternal deaths were due to the hypertensive disturbs, maternal infection and postpartum deaths were due to hypertensive disorders, postpartum infection and postpartum complications [10], whereas Calderon, et al [11] reflects that most of the maternal deaths are because of avoidable causes, as bleeding and infections. Likewise, Afio et al [4] detected in their research that, from the evaluated maternal deaths, more than the half (64.3\%) was considered avoidable.

It is emphasized that the importance of the prevention actions against the maternal mortality, glimpsing the rate decline, mainly from the causes consi- 
dered avoidable. In this perspective, it is understood that Brazil has implanted operational measures and goals to the mortality indicator reduction, but the cast of other factors like education, social, economic and cultural conduction may interfere on the improvement of those indicators.

Thus, some measures may contribute to the efficiency of the maternal death prevention, as the risk classification greeting, the guarantee of quality assistance during the prenatal and the precocious routing of the cases that presents some complication [4].

Either, Sousa et al [12] recommends that all the countries ensure the precocious diagnosis and the urgency treatment and maternal emergences to finally, provide to the natural human reproduction process the lower risk quantity.

The maternal mortality measure is represented by the maternal mortality coefficient/rate/reason, what is calculated through the relation between the maternal death number in a determined place and period and the total of born alive at the same place and period, multiplying the result per 10.000 or 100.000 [13]. According to Dias et al [5], this indicator represents in an excellent way the women and general population health level.

Moreover, other variables may contribute to the maternal death number increasing, as kind of childbirth and parity [14], as well as to influence positively or negatively the maternal health levels in certain population. In the same way, the prenatal appointment number conducted by the pregnant is related to her health enclosure. According to Andrada et al [4], from the women who died, the most part (42.9\%) didn't appear or appeared only to 5 prenatal queries.

Considering the necessity to investigate the State maternal health data, this worksheet aims to evaluate the prenatal indicators quantity, childbirth by type of delivery, maternal mortality coefficient and maternal death number in Rio Grande do Norte, from 2000 to 2014, and to buy with the defined goals to the State and its health regions.

\section{Methodology}

It is about a temporal ecological, descriptive and analytical study, conducted from the secondary data appreciation related to the maternal mortality, in Rio Grande do Norte (RN), during the period from 2000 to 2014, Brazil.

Secondary data were used, composed by the Health Information System Programme: health information system about living newborns (HISNSC) and Mortality Information System (MIS); in a way that the data basis was obtained through official solicitation through legal letter directed to the organs responsible by the target information system of this study, among them the Santa Cruz/RN Municipal Health Office and the $\mathrm{V}^{\text {th }}$ Public Health Regional Unity (V PHRU), with headquarter on the referring city. For that, the variables on which the data was wanted were described and they were received in a spreadsheet file, arranged in tables. In addition, other data-also composed of SINASC and SIM-were extracted from the public domain system of the Health Ministry called DATASUS, with search filters by health region, and also obtained tables in 
a spreadsheet.

Representative data from the 167 cities in Rio Grande do Norte were analyzed, laid in eight Public Health Regional Unity (PHRU), in a way that the first PHRU comprises twenty and seven cities, with the headquarter in São José de Mipibu; the second PHRU is composed by sixteen cities, with the headquarter in Mossoró; the third and the fourth PHRU there are twenty and five cities each, their headquarters are São João Câmara and Caicó, respectively; the $5^{\text {th }}$ PHRU, with twenty and one, being the headquarter in Santa Cruz; the $6^{\text {th }}$ there are thirty and six and its headquarter is in Pau dos ferros; the $7^{\text {th }}$ PHRU comprises five cities with the headquarter in the metropolitan region, and other twelve cities compose the $8^{\text {th }}$ PHRU which headquarter is in Açu.

Referring to the variable, were considered the quantity of women who passed by till six prenatal queries; quantity of women who passed by six or more prenatal queries; quantity of newborns by vaginal childbirth; quantity of newborns through cesarean section; maternal mortality coefficient; number of maternal deaths by residence and number of maternal deaths investigated on the module.

Thus, the data were transferred to the Statistical Package for Social Science (SPSS) software version 22.0, serial number: 10101141047, after the construction of the database for each variable described according to the year and the health region. In this software, they were stored and treated through the variable nature and the statistical tests application indicated to this study, obtaining averages, medians, standard-deviation and values minimum and maximum, besides the ANOVA test calculum conduction, adopting the test value equal or less than $5 \%$ and using a confidence interval of $95 \%$. The database fields with any data were treated as the non occurrence of the event in question, once there were other camps treated as ignored, with the distinction. Furthermore, to the map confection, was used the Tabwin software and the graphic basis of the $\mathrm{RN}$ map by health region, both belonging to the Health Ministry, which access is free.

For comparison purposes and for treating about a State goal, were used information of the agreed programming per cities, health region, states and by the Federal District, according to the agreement process of guidelines, objectives, goals and indicators, aiming to fortify the Public Health System (PHS) and the implementation of the Organizational Contract for Public Health Action-OCPHA [15].

Thus, the established goals were observed regarding the maternal death indicator to 2012, 2013, 2014 in Rio Grande do Norte, because only the documents related to the agreement of those years were available to be accessed on the SISPACTO website, so was observed the same indicator to 2015, in each PHRU.

\section{Results}

After the data analysis, was possible to examine that, in relation to the conduction of prenatal appointment quantity, the quantity of women who undergone up to six prenatal queries following a decline pattern from 2000 to 2014, being that, at the first, this number was equal to 36.873 and, on the last, was 18944 . 
On the other hand the number of women who undergone through seven or more prenatal appointment follows a increase pattern during the years, being that, in 2000 , were 18.101 and in 2014 were 28.333 women to pass through seven or more prenatal queries. Those data evolution may be observed on the Graphic 1.

It was observed that, in 2000, the proportion that undergone up to six prenatal appointment was of $66.20 \%$, while the ones who passed through seen or more queries corresponded to $32.49 \%$. During the last studied year, was obtained a proportion of $39.95 \%$ of the women with a maximum of six queries, and 59.75 conducted seven or more prenatal queries. Those data evolution may be observed on the Graphic 2.

The number of prenatal queries and the number of maternal death reveals that, from 2001 to 2010, there were a correlation statistically significant between the number of women who conducted from zero to six prenatal queries and the maternal death number that occurred during the same year, while there was also a significant correlation between the number of women who conducted seven or more prenatal queries and the death number from 2010 to 2013. Those data and all the chi-square test values may be seen on Table 1 .

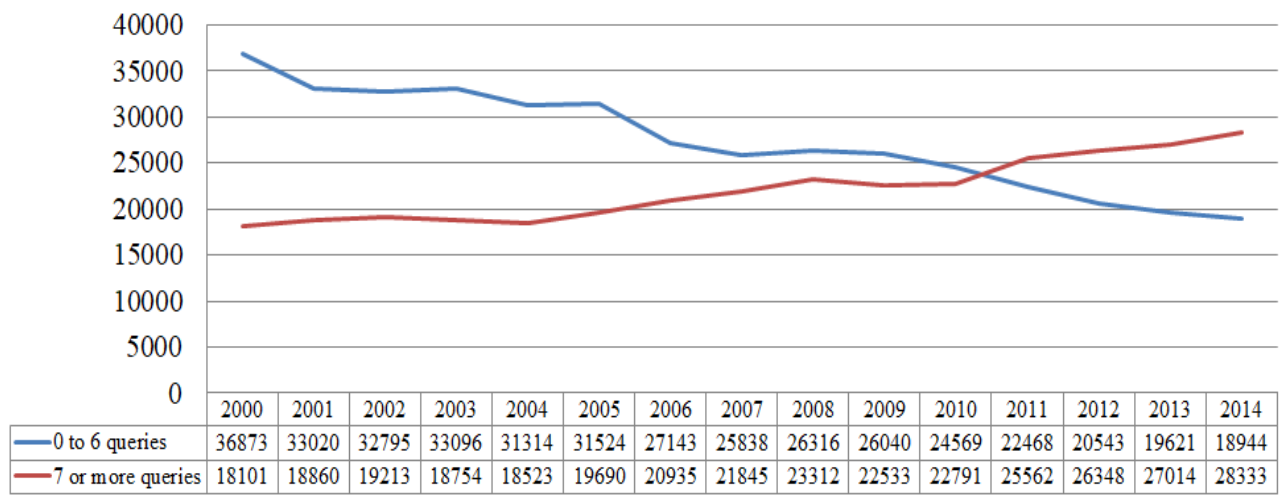

Graphic 1. Evolution on the quantity of women who performed from zero to six prenatal queries and the ones who performed seven or more queries, during the period from 2000 to 2014, Rio Grande do Norte, Brazil, 2016.

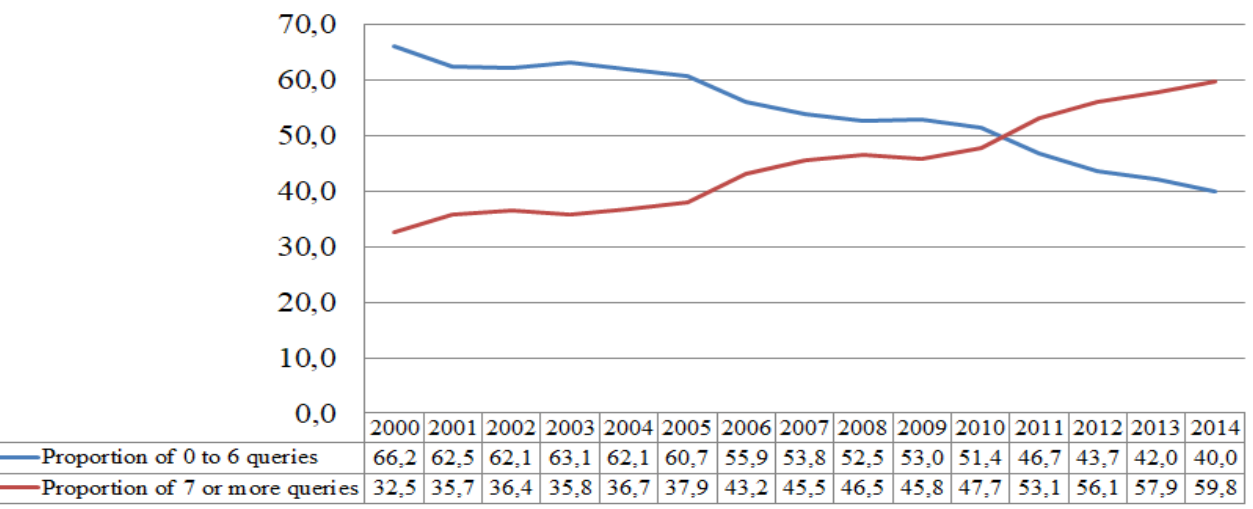

Graphic 2. Evolution of the proportion of women who performed from zero to six prenatal queries and the ones who conducted more than seven queries, from 2000 to 2014, Rio Grande do Norte, Brazil, 2016. 
Table 1. Distribution of the maternal death average according to the prenatal queries quantity, from 2000 to 2014, in Rio Grande do Norte, Brazil, 2016.

\begin{tabular}{|c|c|c|c|c|c|}
\hline \multirow[b]{2}{*}{ YEAR } & \multicolumn{3}{|c|}{ Averages } & \multicolumn{2}{|c|}{$P$ value } \\
\hline & $\begin{array}{c}0 \text { to } 6 \text { prenatal } \\
\text { queries }\end{array}$ & $\begin{array}{c}7 \text { or more } \\
\text { prenatal queries }\end{array}$ & $\begin{array}{c}\text { Maternal deaths } \\
\text { at home }\end{array}$ & 0 to 6 queries & $\begin{array}{c}7 \text { or more } \\
\text { queries }\end{array}$ \\
\hline 2000 & 220.7964 & 108.3892 & 0.1257 & $<0.001$ & $<0.001$ \\
\hline 2001 & 197.7246 & 112.9341 & 0.0838 & 0.005 & $<0.001$ \\
\hline 2002 & 196.3772 & 115.0479 & 0.1018 & $<0.001$ & $<0.001$ \\
\hline 2003 & 198.1796 & 112.2994 & 0.1737 & $<0.001$ & $<0.001$ \\
\hline 2004 & 187.5090 & 110.9162 & 0.1138 & $<0.001$ & $<0.001$ \\
\hline 2005 & 188.7665 & 117.9042 & 0.1677 & $<0.001$ & $<0.001$ \\
\hline 2006 & 162.5329 & 125.3593 & 0.0719 & $<0.001$ & $<0.001$ \\
\hline 2007 & 154.7186 & 130.8084 & 0.0898 & $<0.001$ & $<0.001$ \\
\hline 2008 & 157.5808 & 139.5928 & 0.1257 & $<0.001$ & $<0.001$ \\
\hline 2009 & 155.9281 & 134.9281 & 0.1377 & $<0.001$ & $<0.001$ \\
\hline 2010 & 147.1198 & 136.4731 & 0.1078 & 0.002 & 0.001 \\
\hline 2011 & 134.5389 & 153.0659 & 0.2216 & $<0.001$ & $<0.001$ \\
\hline 2012 & 123.0120 & 157.7725 & 0.1976 & $<0.001$ & $<0.001$ \\
\hline 2013 & 117.4910 & 161.7605 & 0.1317 & $<0.001$ & 0.008 \\
\hline 2014 & 113.4371 & 169.6587 & 0.1677 & $<0.001$ & $<0.001$ \\
\hline
\end{tabular}

About the number of newborns through childbirth in Rio Grande do Norte, during the studied period, there was a decline when it was occurred through vaginal childbirth and, contrarily, an increase on the number of the alive cesarean newborns, with the years' progress. Thus, in 2000, the number of alive vaginal newborns was equal to 40.405 , meanwhile in 2014, this number was of 18.941 . Regarding the cesarean newborn number, in 2000, was obtained 15.294 and, in 2014, were 28.468. The evolution of those data may be observed on Graphic 3.

In this context, the proportion of newborn number through vaginal childbirth declined from $72.54 \%$ in 2000 , to $39.95 \%$ in 2014 ; while the number of alive newborns through cesarean increased from $27.45 \%$ in 2000 , to $60.04 \%$ in 2014 . Those data evolution may be observed on Graphic 4.

Regarding maternal color/race scores, the highest number were brown women; over the age range of these obits, women between 20 and 29 years of age were the largest number; with respect to the years of study, the highest number of maternal obtices happened to women who had between 4 and 7 years of study, not counting the ignored ones; and, on the marital status, most obits occurred with unmarried women. These complete data can be seen in Table 2 .

Likewise, the Maternal Mortality Coefficient (MMC) per year were analyzed, in each PHRU, being stood out the major average (95.56), in 2014, verified on the $8^{\text {th }}$ PHRU, and the lowest average (20.85) in this year on the third region, as 


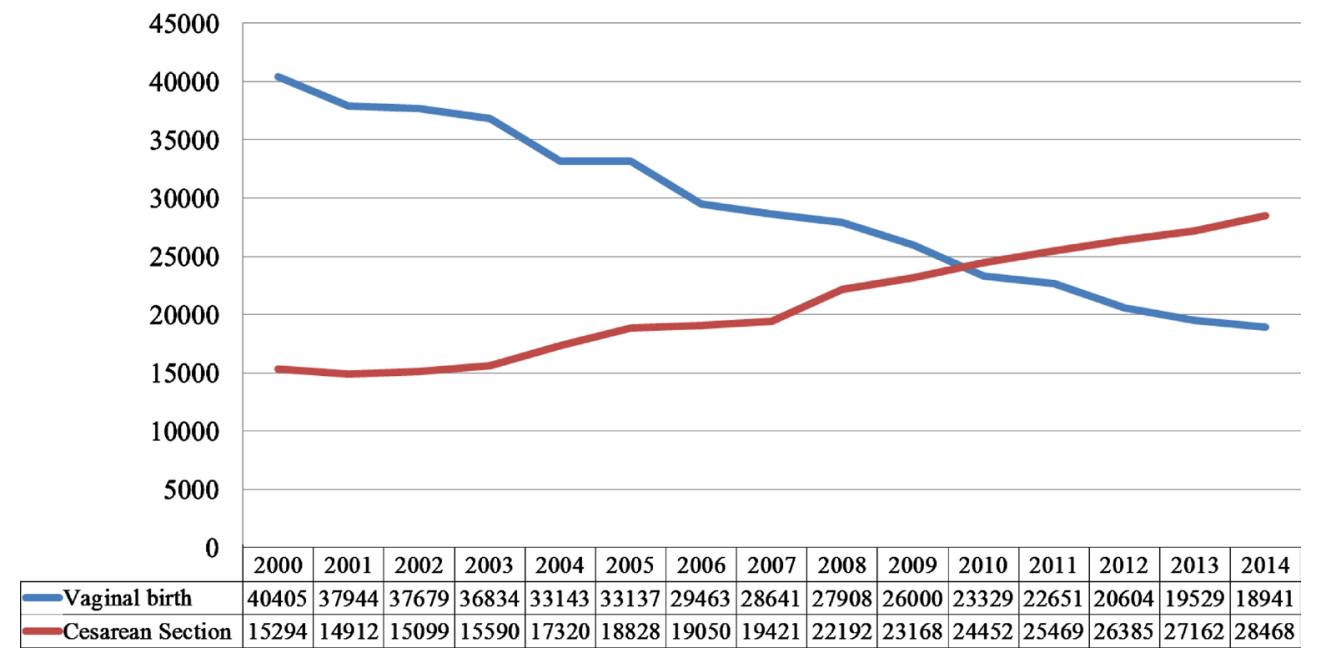

Graphic 3. Evolution of the alive newborns through vaginal and cesarean number, from 2000 to 2014, Rio Grande do Norte, Brazil, 2016.

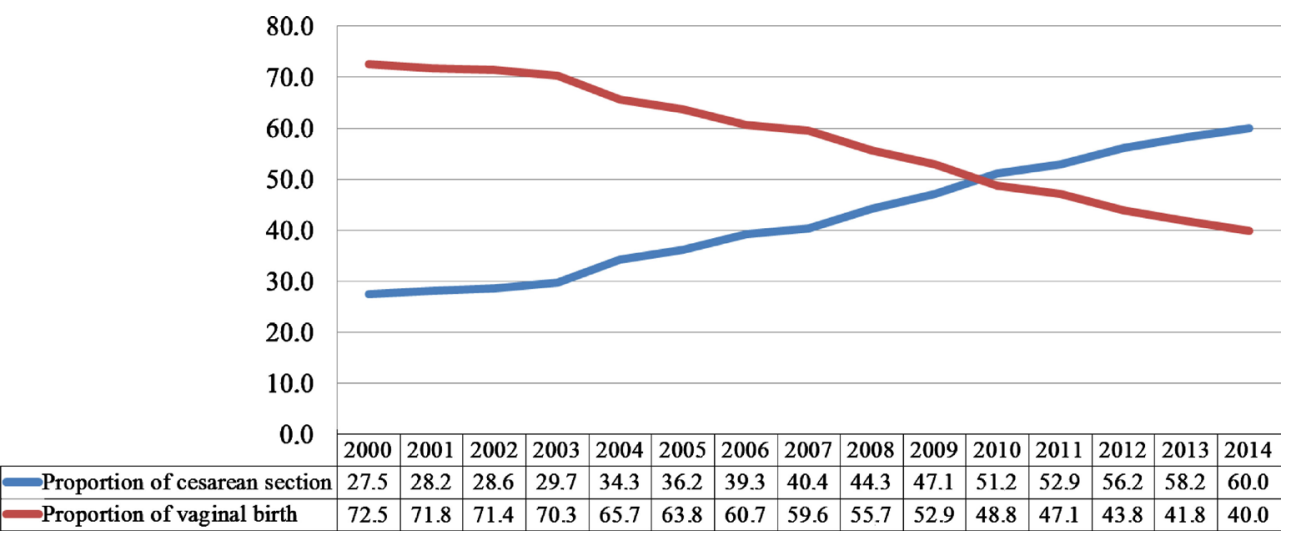

Graphic 4. Evolution of the alive newborns through vaginal and cesarean childbirth proportion, from 2000 to 2014, Rio Grande do Norte, Brazil, 2016.

observed on the Table 3.

On the other hand, the maternal death number by residence varies on the studied period, being that, in 2000, occurred twenty and one deaths for causes related to pregnancy, childbirth and postpartum and, in 2014, occurred twenty and eight, and the year that presented the most number of maternal death was 2011, with thirty and seven deaths.

From the maternal deaths, the number of examined on the web module of the health system was registered since 2006, when it was zero, and presented increases and declines during the observed years, as presented on Table 3.

The number of maternal deaths at home, in Rio Grande do Norte, was compared to the goals established by the SISPACTO to the years of 2012 (goal = 40), 2013 (goal $=20$ ) and 2014 (goal $=20$ ). From this, was observed that, in 2012, occurred thirty and three maternal deaths of women who lived in Rio Grande do Norte; in 2013 occurred twenty and three deaths and, in 2014, occurred twenty and eight maternal deaths, as can be observed on the Graphic 5.

Moreover, the maternal death number measure, in each PHRU, during the 
studied period, it shows that the reality of the previous years is next to the estimated goals on SISPACTO to 2015, being that the PHRU IV was the one that presented a most distant measure when compared to the estimate to 2015, as demonstrated on the Picture 1 and Picture 2.

\section{Discussion}

On this study, the prenatal appointment number evolution, shows that it is occurring a growth on the number of women with more than six queries according to the Graphic 1 data, in a way that this number increased about $63 \%$ from 2000 to 2014 (Graphic 2), representing almost $60 \%$ of the pregnant with seven or more queries, during the last analyzed year. According to Silva et al [16], this increase presupposes the extension of the pregnant access to the prenatal assistance.

Table 2. Data on the sociodemographic characteristics of maternal deaths according to the year, from 2000 to 2014 , Rio Grande do Norte, Brazil, 2016.

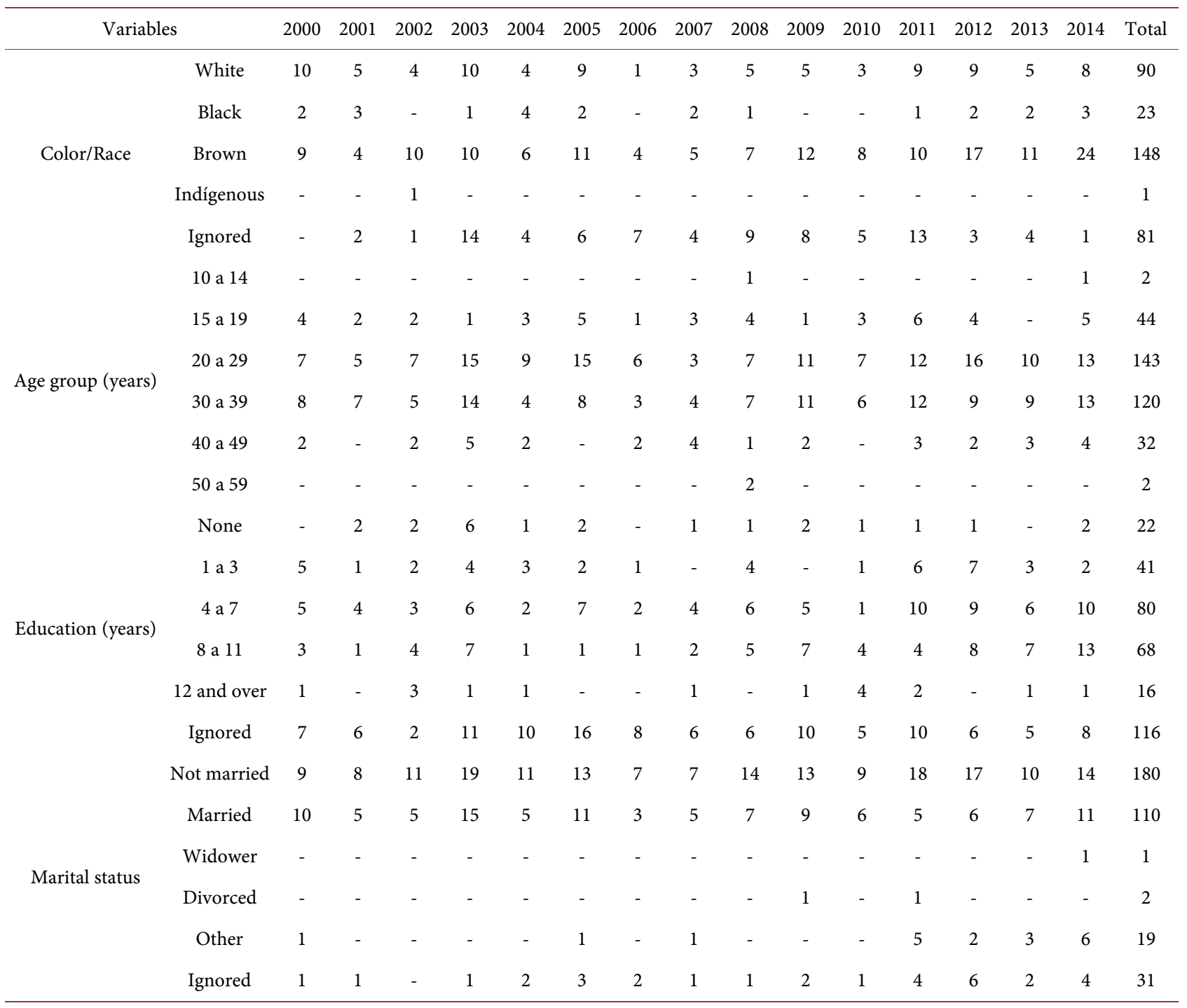


Table 3. Distribution of the Maternal Mortality Coefficient and investigated maternal death number, from 2000 to 2014 , Rio Grande do Norte, Brazil, 2016.

\begin{tabular}{|c|c|c|c|c|c|c|c|c|c|c|c|}
\hline \multirow{2}{*}{ YEAR } & \multicolumn{8}{|c|}{ URSAP } & \multirow{2}{*}{$\mathrm{RN}$} & \multirow{2}{*}{$\begin{array}{c}\text { Investigated } \\
\text { deaths }\end{array}$} & \multirow{2}{*}{$P$} \\
\hline & I & II & III & IV & V & VI & VII & VIII & & & \\
\hline 2000 & $3(43.2)$ & $1(15.0)$ & $1(17.0)$ & $2(41.6)$ & 0 & $1(24.5)$ & $10(46.1)$ & $3(115.6)$ & $21(37.2)$ & - & 0.748 \\
\hline 2001 & 0 & $5(68.6)$ & $1(17.8)$ & $1(20.3)$ & $1(30.6)$ & 0 & $5(25.6)$ & $1(40.1)$ & $14(26.2)$ & - & 0.804 \\
\hline 2002 & $3(48.3)$ & $2(27.0)$ & $1(18.0)$ & $3(64.6)$ & 0 & 0 & $7(36.9)$ & $1(38.6)$ & $17(31.9)$ & - & 0.695 \\
\hline 2003 & $1(15.6)$ & $4(55.4)$ & $4(75.7)$ & $1(22.2)$ & $2(64.4)$ & 0 & $16(81.6)$ & $1(39.0)$ & $29(55.4)$ & - & 0.043 \\
\hline 2004 & 0 & $6(83.8)$ & 0 & $1(23.0)$ & $2(66.3)$ & 0 & $7(36.8)$ & $3(122.2)$ & $19(37.4)$ & - & 0.164 \\
\hline 2005 & $5(86.0)$ & $4(55.6)$ & $2(35.7)$ & $3(67.1)$ & $3(96.9)$ & $1(25.5)$ & $7(36.0)$ & $3(120.6)$ & $28(53.5)$ & - & 0.687 \\
\hline 2006 & 0 & $4(58.7)$ & $1(19.9)$ & 0 & 0 & $1(28.2)$ & $5(26.8)$ & $1(44.1)$ & $12(24.9)$ & $0(0 \%)$ & 0.037 \\
\hline 2007 & $2(37.4)$ & $2(27.4)$ & $2(43.5)$ & $2(46.7)$ & $1(35.5)$ & $1(27.1)$ & $5(27.8)$ & 0 & $15(31.2)$ & $4(26.7 \%)$ & 0.963 \\
\hline 2008 & $4(66.9)$ & $3(42.4)$ & $2(40.1)$ & 0 & $1(34.9)$ & $1(26.7)$ & $7(36.5)$ & $3(138.4)$ & $21(42.2)$ & $4(19.0 \%)$ & 0.000 \\
\hline 2009 & $1(17.2)$ & $4(56.7)$ & $4(84.6)$ & $2(48.1)$ & $2(69.3)$ & 0 & $8(42.6)$ & $2(93.0)$ & $23(47.0)$ & $18(78.3 \%)$ & 0.257 \\
\hline 2010 & $2(35.7)$ & $5(74.7)$ & $2(41.6)$ & $3(75.9)$ & $1(36.2)$ & $1(28.1)$ & $4(21.9)$ & 0 & $18(37.8)$ & $18(100 \%)$ & 0.897 \\
\hline 2011 & $3(50.5)$ & 7 (104.9) & $4(87.7)$ & $3(72.7)$ & $3(112.0)$ & $1(29.3)$ & $15(80.1)$ & $1(45.8)$ & 37 (76.9) & 35 (94.6\%) & 0.538 \\
\hline 2012 & $5(90.4)$ & $4(61.6)$ & $4(90.3)$ & $6(154.9)$ & 0 & 0 & $10(53.0)$ & $4(191.1)$ & $33(70.5)$ & $32(97.0 \%)$ & 0.023 \\
\hline 2013 & $4(71.8)$ & $1(15.0)$ & $2(45.6)$ & $2(53.9)$ & 0 & $4(135.5)$ & $8(42.2)$ & $1(52.0)$ & $22(47.0)$ & $21(95.5 \%)$ & 0.739 \\
\hline 2014 & $5(94.1)$ & $4(60.0)$ & $1(20.9)$ & $2(54.3)$ & $2(72.3)$ & $2(61.8)$ & $10(52.7)$ & $2(95.6)$ & $28(58.2)$ & $24(85.7 \%)$ & 0.541 \\
\hline
\end{tabular}

-: Year in which the investigated maternal deaths weren't registered on the web-module.

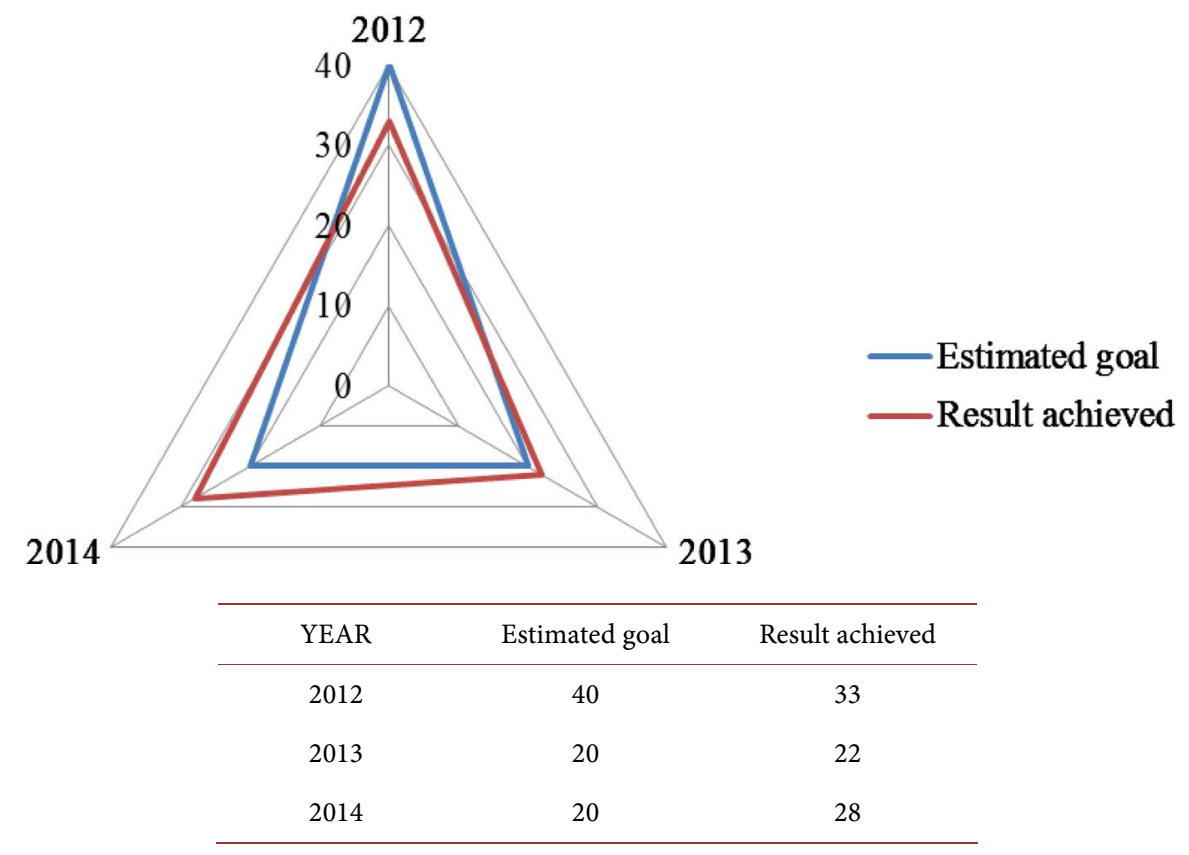

Graphic 5. Relationship between the number of maternal deaths estimated in SISPACTO and the number of deaths occurred according to the SIM, for the years 2012, 2013 and 2014, Rio Grande do Norte, Brazil, 2016. 


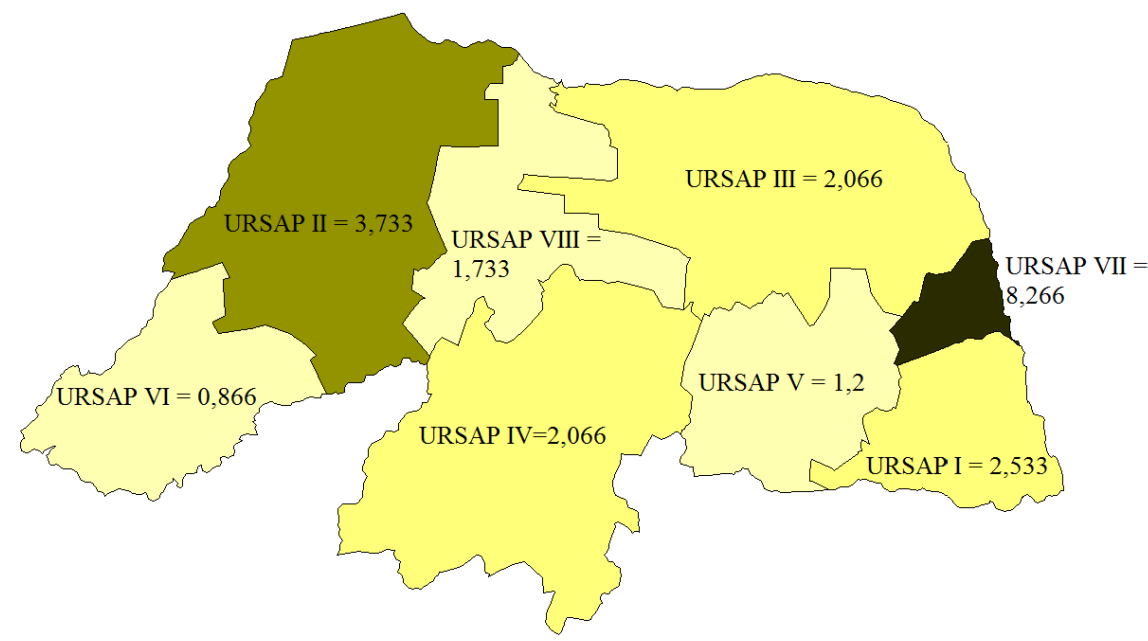

Picture 1. Distribution of the maternal death average number by URSAP, from 2000 to 2014, Rio Grande do Norte, Brazil, 2016.

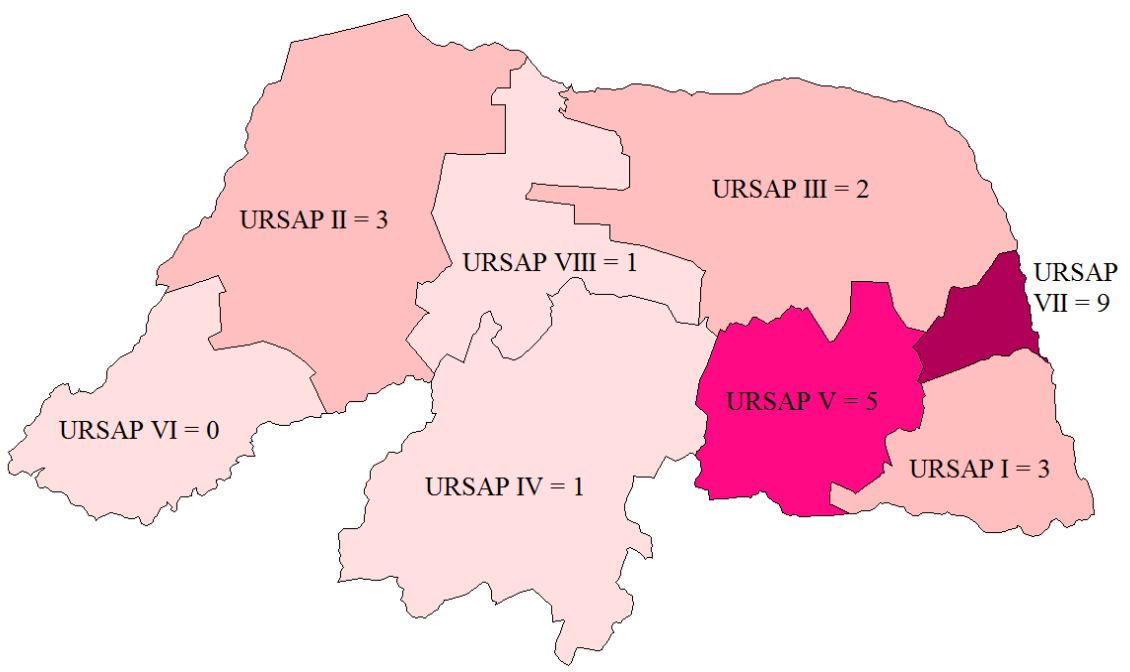

Picture 2. Distribution of the maternal death number agreeded on the SISPACTO to 2015, in each URSAP, Rio Grande do Norte, Brazil, 2016.

In the same way, the Santos Neto et al [1] study demonstrated this evolution, in which the percentage of the pregnant who undergone to seven or more prenatal queries passed that about 30\% to about 50\%, from 1996 to 2005. In the same direction, Assis et al [17] verified that the majority of the pregnant underwent to more than seven prenatal queries. Meanwhile, the Silva et al [18] study, performed in Juazeiro do Norte/CE, from January to June 2010, all the interviewed people conducted from six to thirteen queries.

On the Andrade et al [19] study, 50.4\% of the women could undergo from six to eight prenatal queries. Fonseca et al [20] verified that the percentage of women with seven or more queries kept constant, around $81 \%$, highlighting that, to the teenagers group, this number is declining and, to the older women, it is increasing.

Also, on the Polgliane et al [21] study, $75.6 \%$ of the women conducted six or 
more prenatal queries.

On the Alves et al [22] research, the prenatal appointment average number average was of seven. To Leal et al. [23], the most (75.4\%) of women underwent through six or more prenatal queries. On Viellas et al [24] research, 73.1\% of the pregnants underwent through six or more prenatal queries. On the Silva et al [16] study, there was an annual average increase superior to 28 thousand supported pregnant with more than seven queries, on public or private network.

On the other hand, on Andrada et al [9] study, only $23.8 \%$ of the women underwent to six or more prenatal queries, meanwhile on the Morse et al [25] and Lavado et al [14] studies, $40 \%$ of the women underwent to more than six queries. It is verified that some factors contributes to the occurrence of a lower prenatal appointment number, as the pregnant low schooling [26].

Some studies demonstrate high values to the occurrence of death of mothers who underwent a low prenatal appointment [9] [10] [14]. On this study, was observed the relation between the prenatal appointment number and the maternal death number in only three of the analyzed years, 2001, 2010 and 2013, being that, in 2010, we obtained a statistically significant value as for the number of women who underwent up to six queries as for the number of women who underwent through seven or more prenatal queries, as observed on Table 1.

In this sense, it is highlighted the prenatal importance as a way to control the adverse events caused by the pregnancy period, being the appointment number one of the factors that indicate the prenatal quality. Thereby, the accomplishment of six or more prenatal queries it positively associated to the essential medicine uses, ideally, during the pregnancy [19].

About the evolution of newborn number by kind of childbirth, observed on the Graphic 3, reveals that there is a substantial increase of the number and the cesarean proportion, observed on Graphic 4, in a way that this last increased more than $30 \%$ during the studied period, to the detriment of the absolute declining of more than 20,000 normal childbirths.

Among many aspects that support directly or indirectly to the increasing of the maternal death number, is the kind of childbirth, being important the investigation and discussion of this factor, aiming to the reduction of the maternal mortality and to the developing of the society like a whole [14].

The obtained result in this study was equipped to the found by Brito et al [27], in which $77.1 \%$ of the childbirth occurred by cesarean. Likewise, according to the study of Silva et al [16], which analyzed the data from 1999 to 2013 in Brazil, there were a decline on the normal childbirth and an increasing of $63.68 \%$ on the cesarean occurrences.

On the other hand during the Correia et al [10], the cesarean number was near to the half of the childbirth number $-55.3 \%$, still superior to the normal childbirth.

On the research of Morse et al [25], 50.4\% of the performed childbirth was cesarean. On the study of Soares et al [28], 51\% of the childbirth was cesarean, 
while the research of Lavado et al [14], 44\% of the women had cesarean childbirth and, on the study of Leal et al [23], the cesarean childbirth occurred in $40.9 \%$ of the cases.

This demonstrates the situation of many realities in which the number of cesarean is superior to the recommended by the health national and international guidelines and, in many contexts, this number has been increasing more and more and standing out in relation to the normal childbirth, what meets the prerogative of the health world and national organs, checking out more risks and negative factors related to the maternal health.

According to Andrada et al [9], 57.1\% of the maternal deaths occurred after the cesarean childbirth. Meanwhile, Soares et al [28] verified that, the women who presented disorders signals to the adaptation during the postpartum due to childbirth, $66.7 \%$ had given birth through cesarean. Moreover, it is suggested that a high social economical level is related to the cesarean happening, thus as the major schooling level [26] [29].

To qualify the maternal health attention services, one of the most sensible and important indicators is the maternal mortality coefficient (MMC), which allows the quality evaluation and the services covery. However, it is considerate a low MMC when it is lower than 20 per 100,000 alive newborns, an average when it is between 20 and 49 per 100,000 alive newborns, a high when it is between 50 and 149 per 100,000 alive newborns and very high when the number is more than 150 per 100,000 alive newborns [9].

On this worksheet, the maternal mortality coefficient presented a great variation on the studied period, represented on Table 3, highlighting the fact that, during the last analyzed year, only the III URSAP presented an averaged MMC, while the others presented a high MMC. This reveals a necessity to improve the women health assistance to the prenatal, childbirth and postpartum period, besides to implement health education measures on the community and on the familiar reality.

In the same way, it may be observed on the study of Mota et al [30] that analyzed data from 2001 to 2005 of cities from the Brazilian Southeast, where the maternal mortality rate presented a great variability, from zero to $110.9 / 100$ thousand alive newborns, as well as on the study of Peixoto et al [13], which demonstrated that in Santa Catarina, from 1996 to 2002, occurred irregular oscillations on the Maternal Mortality Reason (MMR).

On the research conducted by Correia et al [10], the Maternal Mortality Reason was of 65.99, with the irregular annual behavior. On the study of Botelho et al [31], in Pará, during 2006 to 2010, the Maternal Mortality Reason was of 51.9, and there weren't significant reduction on this period. It is emphasized the study of Szwarcwald et al [32], that analyzed data in Brazil from 1990 to 2011, where the decrease rate of the MMR was the $3.72 \%$ per year, with multiple correlation coefficient of $0.988(p<0.01)$. In addition to this, he estimated a MMR equal to 61.4/100 thousand alive newborns in Rio Grande do Norte, to the period from 2009 to 2011. 
Regarding the maternal death number of residents in Rio Grande do Norte, it is observed an oscillation among the years (Table 2) without an increasing or declining pattern during this period, being verified that, during the three last studied years, only 2012 presented a death number inside the determined goal by the SISPACTO to the year, while in 2013 and 2014 presented maternal deaths number superior to the proposed goals, as presented on Graphic 5.

In Santa Catarina, from 2000 to 2002, occurred 129 maternal deaths according to official data [13]. A study conducted in Rio de Janeiro revealed that occurred 173 maternal deaths of the residents in the state in 2001 [33], what represents more than ten times the quantity of maternal deaths, in the same year, in Rio Grande do Norte. In the second semester of 2002, in Brazilian Northeast, were identified 53 maternal deaths [34].

Meanwhile, from 2007 and 2009 April, were registered six maternal deaths in the Ribeirão Preto Medicine College Clinical Hospital [35]. Morse et al [25] described that occurred three maternal deaths in the period of 5 months in 2009, in Niterói/RJ.

In Pará, during the period from 2006 to 2010, were identified 383 maternal deaths, in the way that in 2010, resulted in 1902 maternal deaths.

Despite many studies that revealed the maternal death quantity in many places of the country, the reality of those data is still insincere due to the sub-registration and the underreporting 4. Bonciani [36] analyzed the Deaths Declaration (DD) of fertile aged women and concluded that there were 114 cases of maternal deaths, from which, 48 didn't tell this cause on the DD.

It is highlights that, in addition to know the real maternal death number, is also important to know the science of the factors that can contribute to the increasing of the maternal mortality, among those is the schooling level, in a way that, as lower is the women instruction level, higher the risk to die for causes linked to the pregnancy, childbirth or postpartum [9].

Thereby, to be identified the maternal death causes and the factors that contributed to this fact, it is necessary the inquiry of the cases in an individualized way. On the present study, the number of maternal deaths investigated on the web-module of the health system, presented on Table 3, was registered only from 2006, when it occurred twelve, anyone more was investigated. During the years, there was the investigated death register, however, only in 2010, all the occurred deaths were investigated.

Finally, the maternal deaths average number per year, in each URSAP, during the studied period (Picture 1), revealed that there is a proximity with the estimated goals to 2015 (Picture 2), demonstrating the importance of the indicators found in the regions, above what was preconized on the goal and, with this, presenting the necessity of prevention practices on the grievance prevalent on the maternal health. It is, through the fortification of the aspects that determine the maternal health, it can be increased the possibility to achieve the agreed goals on the SISPACTO, achieving the improvement on the mother's life quality and also 
on the general population.

\section{Conclusions}

The present research enables to conclude that the maternal health, in Rio Grande do Norte, is presenting indicators that need a quality monitoring, mainly in relation to the prenatal, childbirth and the maternal mortality.

On the study, it is also possible to identify positive points, as an increasing on the number of women who undergone to seven or more prenatal queries and the number of investigated maternal death that achieved almost $100 \%$ of the total of deaths occurred on the last evaluated years. In the other hand as negative points, it is stood out the increasing number of cesarean newborns and, consequently, the decline of alive newborns by cesarean and, consequently, the decline of alive newborns by normal childbirth and high maternal mortality rate, on the last studied year, above the established goal.

Therefore, it is justified to suggest to the city and state management, the implementation of actions of fortification to adherence to the normal childbirth, having as basis the information disposition related to risks, benefits and right to choose in this aspect to women in fertile age, besides incentives to the health professionals linked to this factor.

It is recognized as study limitation the possibility of the data has been underreported, due to the use of the SIM and SINASC Information Systems. On the other hand, it is highlighted the relevance of data by been of national basis, representing official statistics.

For now, considering the reality in Brazil and its states, among them Rio Grande do Norte, there is the necessity to guarantee a women health quality assistance, understood by familiar, prenatal, childbirth and postpartum planning, what is listed on the operational guideline to the pact by the life, proposed on the Public Health System.

\section{References}

[1] Santos Neto, E.T., Alves, K.C.G., Zorzal, M. and Lima, R.C.D. (2008) Maternal Health Policies in Brazil: The Links with Maternal and Child Health Indicators. Health and Society, 17, 107-119.

http://www.scielo.br/scielo.php?script=sci_arttext\&pid=S0104-12902008000200011 \&lng $=\mathrm{pt}$

[2] Liboreiro, L.F.N. (2006) A Goals of the Millennium: Distant Goals. PUC Minas, Belo Horizonte.

[3] Angulo-Tuesta, A., Santos, L.M.P. and Natalizi, D.A. (2016) Impact of Health Research on Advances in Knowledge, Research Capacity-Building and Evidence-Informed Policies: A Case Study on Maternal Mortality and Morbidity in Brazil. Sao Paulo Medical Journal, 134, 153-162. http://www.scielo.br/scielo.php?script=sci_arttext\&pid=S1516-31802016000200153

[4] Áfio, A.C.E., Araújo, M.A.L., Rocha, A.F.B., Andrade, R.F.V. and Melo, S.P. (2014) Maternal Deaths: The Need to Rethink Coping Strategies. Northeast Network Nursing Journal, 15, 631-638. 
http://www.revistarene.ufc.br/revista/index.php/revista/article/viewFile/1741/pdf

[5] Dias, J.M.G., Oliveira, A.P.S., Cipolotti, R., Monteiro, B.K.S.M. and Pereira, R.O. (2015) Maternal Mortality. Medical Journal of Minas Gerais, 25, 173-179. http://www.rmmg.org/article/details/1771

[6] Tognini, S. (2014) Tendency of Maternal Mortality in the Region of Grande ABC Paulista from 1997 to 2011. USP, São Paulo.

[7] World Health Organization (1997) ICD-10 International Statistical Classification of Diseases and Related Health Problems. University of São Paulo, São Paulo.

[8] Ministry of Health (BR). Department of Health Care. Department of Strategic Programmatic Actions. Manual of Maternal Mortality Committees. Ministry of Health.

[9] Andrada, A.A.C., Vitorello, D.A. and Saab Neto, J.A. (2003) Maternal Mortality in the State of Santa Catarina during the Year 2001. Medical archives of Santa Catarina, 32, 56-64. http://www.acm.org.br/revista/pdf/artigos/152.pdf

[10] Correia, R.A., Araújo, H.C., Furtado, B.M.A. and Bonfim, C. (2011) Epidemiological Characteristics of Maternal Deaths Occurred in Recife, PE, Brazil (2000-2006). Brazilian Journal of Nursing, 64. http://www.scielo.br/scielo.php?script=sci_arttext\&pid=S0034-71672011000100014

[11] Calderon, I.M.P., Cecatti, J.G. and Vega, C.E.P. (2006) Beneficial Interventions in Prenatal Care to Prevent Maternal Mortality. Brazilian Journal of Obstetrics and Gynecology, 28, 310-315.

http://www.scielo.br/scielo.php?script=sci_arttext\&pid=S0100-72032006000500008

[12] Sousa, M.H., Cecatti, J.G., Hardy, E.E., Amaral, E., Souza, J.P.D. and Serruya, S. (2006) Health Information Systems and Monitoring of Severe Maternal Morbidity and Maternal Mortality. Brazilian Journal of Maternal and Child Health, 6, 161-168. http://www.scielo.br/scielo.php?script=sci_arttext\&pid=S1519-38292006000200002 \&lng=en

[13] Peixoto, H.C.G., Martins, H.E.L., Gregorio, P.V.R. and Knobel, R. (2006) Maternal Mortality Profile in Santa Catarina. Global Nursing Journal, 8, 1-11. http://revistas.um.es/eglobal/article/viewFile/326/434

[14] Lavado, M.M., Poerner, C.A., Tomaz, T.S.O., Morelli, M., Ramos, L.R., Koch, T.F. and Santos, B. (2012) Epidemiological Profile of Maternal Deaths in Itajaí in the Period 1997-2007. Medical Archives of Santa Catarina, 41, 28-33. http://www.acm.org.br/revista/pdf/artigos/908.pdf

[15] Ministry of Health (BR) (2015) Secretariat of Strategic and Participatory Management. Department of Interfederative Joint, Brasília.

[16] Silva, A.L.A., Mendes, A.C.G., Miranda, G.M.D. and Santos Neto, P.M. (2016) Birth Assistance in Brazil: A Critical Situation Not Yet Overcome 1999-2013. Brazilian Journal of Maternal and Child Health, 16, 139-148. http://www.scielo.br/pdf/rbsmi/v16n2/en_1519-3829-rbsmi-16-02-0129.pdf

[17] Assis, T.R., Viana, F.P. and Rassi, S. (2008) Study of the Main Maternal Risk Factors in Hypertensive Gestational Syndromes. Brazilian Archives of Cardiology, 91, $11-17$.

http://www.scielo.br/scielo.php?script=sci_arttext\&pid=S0066-782X2008001300002

[18] Silva, R.M., Costa, M.S., Matsue, R.Y., Sousa, G.S., Catrib, A.M.F. and Vieira, L.J.E.S. (2012) Cartography of the Health Care of Pregnant Women. Ciênc Collective Health, 17, 635-642. http://www.scielo.br/pdf/csc/v17n3/v17n3a09

[19] Andrade, A.M., Ramalho, A.A., Koifman, R.J., Dotto, L.M.G., Cunha, M.A. and 
Opitz, S.P. (2014) Factors Associated with the Use of Drugs in Gestation in Primigravidae in the Municipality of Rio Branco, Acre, Brazil. Cadernos de Saúde Pública, 30, 1042-1056.

http://www.scielo.br/pdf/csp/v30n5/0102-311X-csp-30-5-1042.pdf

[20] Fonseca, S.C., Monteiro, D.S.A., Pereira, C.M.S.C., Scoralick, A.C.D., Jorge, M.G. and Rozario, S. (2014) Inequalities in Prenatal Care in Southeastern Brazil. Ciênc Collective Health, 19.

http://www.scielo.br/scielo.php?script=sci_arttext\&pid=S1413-81232014000701991

[21] Polgliane, R.B.S., Leal, M.C., Amorim, M.H.C., Zandonade, E. and Santos Neto, E.T. (2014) Adequacy of the Process of Prenatal Care According to the Criteria of the Program of Humanization of the Prenatal and Birth and of the Organization of the World. Ciênc Collective Health, 19, 1999-2010.

http://www.scielo.br/scielo.php?script=sci_arttext\&pid=S1413-81232014000701999

[22] Alves, A.S., Coutinho, I., Segatto, J.C.M., Silva, L.A., Silva, M.D.S. and Katz, L. (2014) Evaluation of the Adequacy of the Screening and Diagnosis of Gestational Diabetes Mellitus in Puerperal Patients Attended at a Hospital in Two Municipalities in the Region of the São Francisco Valley Northeastern Brazil. Brazilian Journal of Maternal and Child Health, 14.

http://www.scielo.br/scielo.php?script=sci_arttext\&pid=S1519-38292014000100039

[23] Leal, M.C., Theme-Filha, M.M., Moura, E.C., Cecatti, J.G. and Santos, L.M.P. (2015) Attention to Prenatal and Delivery in Women Users of the Public Health System Resident in the Legal Amazon and in the Northeast, Brazil 2010. Brazilian Journal of Maternal and Child Health, 15, 91-104.

http://www.scielo.br/scielo.php?script=sci_arttext\&pid=S1519-38292015000100091

[24] Viellas, E.F., Domingues, R.M.S.M., Dias, M.A.B., Gama, S.G.N., Theme Filha, M.M., Costa, J.V., Bastos, M.H. and Leal, M.C. (2014) Prenatal Care in Brazil. Cadernos de Saúde Pública, 30, 85-100. http://www.scielo.br/pdf/csp/v30s1/0102-311X-csp-30-s1-0085.pdf

[25] Morse, M.L., Fonseca, S.C., Gottdtroy, C.L., Waldmann, C.S. and Gueller, E. (2011) Severe Maternal Morbidity and Near Misses in Regional Reference Hospital. Brazilian Journal of Epidemiology, 14, 310-322.

http://www.scielo.br/scielo.php?script=sci_arttext\&pid=S1415-790X2011000200012

[26] Haidar, F.H., Oliveira, U.F. and Nascimento, L.F.C. (2001) Maternal Education: Correlation with Obstetric Indicators. Cadernos de Saúde Pública, 17, 1025-1029. http://www.scielo.br/pdf/csp/v17n4/5309.pdf

[27] Brito, K.K.G., Moura, J.R.P., Sousa, M.J., Brito, J.V., Oliveira, S.H.S. and Soares, M.J.G.O. (2015) Prevalence of Gestational Hypertensive Syndromes (SHEG). Revista de Pesquisa: Cuidado é Fundamental Online, 7, 2717-2725.

http://www.seer.unirio.br/index.php/cuidadofundamental/article/view/3749/pdf_1610 https://doi.org/10.9789/2175-5361.2015.v7i3.2717-2725

[28] Soares, G.C.F., Andretto, D.A., Diniz, C.S.G. and Narchi, N.Z. (2013) Postnatal Postpartum Adaptation Disorders: An Exploratory Descriptive Study. Online Brazilian Journal of Nursing, 11.

http://www.objnursing.uff.br/index.php/nursing/article/view/3884/html_2

[29] Friche, A.A.L., Calaffa, W.T., César, C.C., Goulart, L.M.F. and Almeida, M.C.M. (2006) Indicators of Maternal and Child Health in Belo Horizonte, Minas Gerais, Brazil, 2001: Analysis of Intra-Urban Differentials. Cadernos de Saúde Pública, 22, 1955-1965.

http://www.scielo.br/scielo.php?script=sci_arttext\&pid=S0102-311X2006000900027 
[30] Mota, A.K.M., Miranda Filho, A.L., Saraceni, V. and Koifman, S. (2012) Maternal Mortality and Incidence of Dengue in the Southeast Region of Brazil: Ecological Study in the Period 2001-2005. Cadernos de Saúde Pública, 28, 1057-1066. http://www.scielo.br/pdf/csp/v28n6/05.pdf

[31] Botelho, N.M., Silva, I.F.M.M., Tavares, J.R. and Lima, L.O. (2014) Causes of Maternal Death in the State of Pará, Brazil. Brazilian Journal of Obstetrics and Gynecology, 36

http://www.scielo.br/pdf/rbgo/v36n7/0100-7203-rbgo-s0100-720320140004892.pdf

[32] Szwarcwald, C.L., Escalante, J.J.C., Rabello Neto, D.L., Souza Junior, P.R.B. and Victora, C.G. (2014) Estimation of the Ratio of Maternal Mortality in Brazil, 2008-2011. Cadernos de Saúde Pública, 30, 71-83. http://www.scielo.br/pdf/csp/v30s1/0102-311X-csp-30-s1-0071.pdf

[33] Barbastefano, P.S. and Vargens, O.M.C. (2009) Prevention of Maternal Mortality: A Challenge for Nurses. Brazilian Journal of Nursing, 62, 278-282.

http://www.scielo.br/pdf/reben/v62n2/a17v62n2.pdf

[34] Luizaga, C.T.M., Gotlieb, S.L.D., Jorge, M.H.P.M. and Laurenti, R. (2010) Maternal Deaths: Revision of Correction Factor for Official Data. Epidemiology and Health Services, 19, 7-14.

http://www.producao.usp.br/bitstream/handle/BDPI/13503/art_LUIZAGA_Mortes 2010.pdf?sequence $=1$

[35] Gil, M.M. and Gomes-Sponholz, F.A. (2013) Declarations of Deaths of Women of Childbearing Age: Search for Maternal Deaths. Brazilian Journal of Nursing, 66, 333-337. http://www.scielo.br/pdf/reben/v66n3/a05v66n3.pdf

[36] Bonciani, R.D.F. (2006) Maternal Mortality: An Analysis of the Use of Presumed Causes List. USP, São Paulo. 